\title{
Towards the evolution of the mHealth in mental health with youth: the cyber-space used in psychological rehabilitation is becoming wearable into a pocket
}

\author{
Daniele Giansanti \\ Istituto Superiore di Sanità, Rome, Italy \\ Correspondence to: Daniele Giansanti. Istituto Superiore di Sanità, Rome, Italy. Email: gianslele@gmail.com.
}

\begin{abstract}
The study is focused into the field of tele-mental health with youth. It has three polarities. The first polarity consists on the analysis of the state of art of the guide-lines and reports the recent situation depicted by the American Telemedicine Association and the American Psychiatric Association. The second polarity faces the recent evolution related to the tools available in mHealth to activate remote psychological rehabilitation processes. These tools are today also based on a wearable cyberspace comprehending virtual (VR) and augmented reality (AR). The third polarity concludes the study by opening and submitting basic questions on the related activity of the stake-holders, scholars, regulation bodies and workgroups and showing some example of this activity.
\end{abstract}

Keywords: mHealth; smartphone; medical images

Received: 21 August 2019; Accepted: 25 October 2019; Published: 05 April 2020.

doi: $10.21037 /$ mhealth.2019.11.02

View this article at: http://dx.doi.org/10.21037/mhealth.2019.11.02

\section{Introduction}

The recent article "American Telemedicine Association Practice Guidelines for Telemental Health with Children and Adolescents" by Myers et al. (1) represents a basic document, generated by an American Telemedicine Association (ATA) working group that provides a clinical guideline for the delivery of child and adolescent mental health and behavioral services. This article together with the successive article by Shore $e t$ al. "Best Practices in Videoconferencing-Based Telemental Health April 2018" (2) and together with a further group of articles and contributes (3-10) cited in (2), produced by working groups of the ATA and APA (American Psychiatric Association), represents in this field a complete kit of address resources for tele-mental applications (Table 1).

The guide (1) highlights also specifically as future developments (in the section Future directions in telemental health with youth) with regards to the eHealth and mHealth that telemental health "in consideration to the need of the youth and family in the future should consider the integration with the social media, the asynchronous mental health, m-health, virtual technologies, virtual reality, augmented reality, intelligent wearable devices, and artificial intelligence-all to improve the quality and effectiveness of youth-centered care for all young people in need of mental healthcare services."

The evolution of the mHealth in mental health with youth: between THE forecast and the actual reality

The forecasts in the guide (1) detected in 2017 have perfectly made center with the scenario of evolution in this field and many aspects that in 2017 were futurist, now are reality. Today telemental health is particularly focused to the relationship between the youth and the smartphone both in relation to the attention to the new psychological pathologies and in relation to the new models of care that are oriented to navigate on the mHealth.

(I) In details, with regards to the youth we generally are today assisting to: an increasing interest on mental health of young subjects: in particular, recently special attention is devoted to the relation 
Table 1 The complete kit of resources by APA and ATA for telemental applications

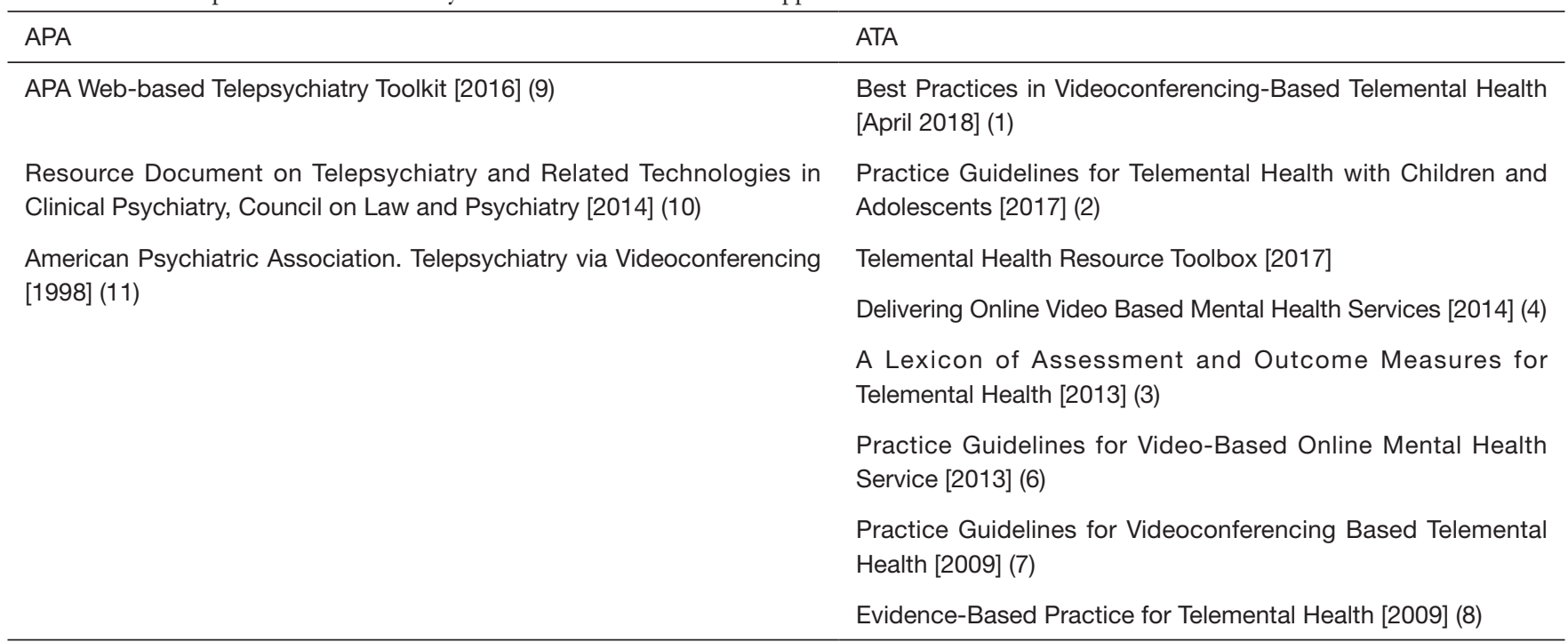

APA, American Psychiatric Association; ATA, American Telemedicine Association.

with the new forms of addiction caused by the mobile-technologies.

(II) The creation of Apps for an asynchronous by remote psychological self therapy based on virtual reality (VR) and augmented reality (AR) with and without exergames, App based on exergames.

(III) The creation of Apps for the self awareness and empowerment for the correct use of the smartphone, as for example Apps that returns information on the time of use of different smartphone applications.

(IV) An increasing interest to the design and assess models of care with a high technological content for providing psychological therapy to young subjects using the same technologies and/tools with whom they are familiar.

The connector of these issues is the Cyber Psychology (Cyb-Psy), which is evolving and adapting to navigate over the WWW more recently through the $m$-bealth and that now it is expanding its focus and field. As it is well known the Cyb-Psy, historically makes a large use of the Cyberspace (VR, AR) in psychological rehabilitation (12-14), by means also the use of large environments arranged with VR and AR tool-kits, named "cave" and very recently we are witnessing to the use of Apps with AR and VR contents in mobile-technology. Today the Cyb-Psy is also focusing to the psychological problems of the young people, the so called mobile-borns. These problems are due to the interaction with the cybernetic systems, today mainly represented by the mobile-technologies. As it is recently emerged, the excessive use of smartphone Apps can lead to new forms of addiction, anxiety and depression $(15,16)$ and/or to new disturbs identified with new curious definitions such as the nomophobia, the ringxiety, the vamping (17). The approach of the Cyb-Psy with the young subjects is currently integrating into the mobile-technologies by using the means indicated above, however this approach is showing useful also for other pre-existing pathologies and for a wide-spectrum of subjects (not only the young ones). New figures are also emerging such as the cyber-psychologist or the augmented-psychologist. Figure 1 shows the expansion of the Cyb-Psy: in particular: the VR and AR are moving from a large cave into the inside of the smartphone: the cyberspace is becoming wearable into a pocket.

\section{The new components of care based on the cyber-psychology: the cyberspace and the SW- applications are becoming wearable into a pocket}

What is happening is that today the psychological interventions are going to use more and more the mobiletechnologies and based on a widened Cyb-therapy (Cyb-t), de-facto resting on to the following components:

(I) Cyb-t1. Chat tools to connect with the therapists and also with other actors, such as the familiars. 


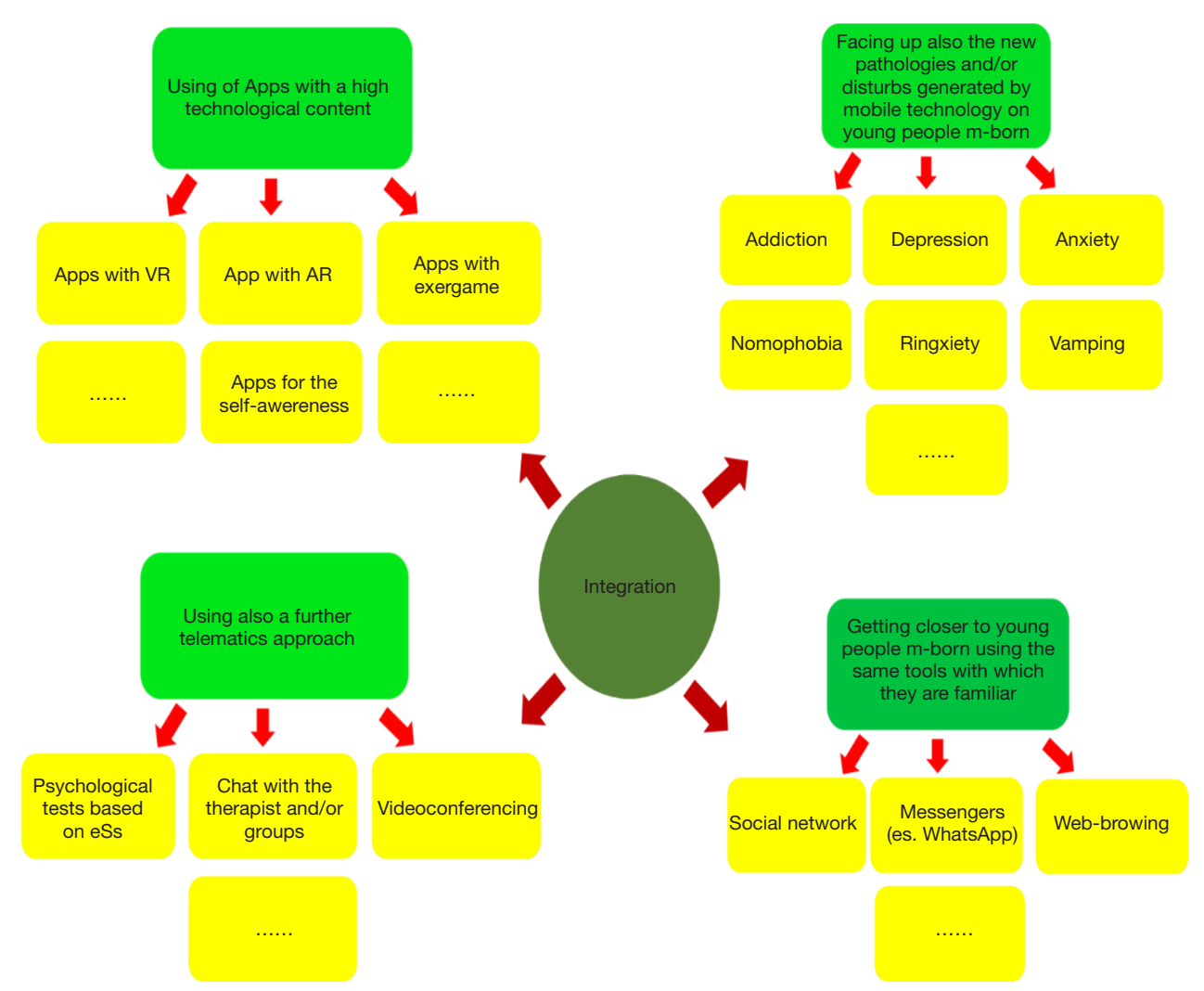

Figure 1 Expansion of the cyber-psycology in the mobile-technology.

(II) Cyb-t2. Video-conferencing tools with a professional.

(III) Cyb-t3. Integration of the therapy also with Apps with $\mathrm{VR}$ and/or AR contents for an asynchronous self-therapy (they are able to return indexes related to each trial to the remote therapist).

(IV) Cyb-t4. Integration of the therapy with Apps for an asynchronous self-awereness aid to avoid an abuse of the time spent with the smartphone (they are able to return indexes related to an assessment of the time spent on the smartphone, useful to send to remote therapists).

(V) Cyb-t5. Psychological tests based on electronic surveys $(\mathrm{eS})$ s and provided onto the mobiletechnologies.

There are recently available, for example software solutions that allow the remote eSs submissions (using for example the messengers, as for example WhatsApp) and the automatic data collecting into a cloud through a clientserver architecture.

While Cyb-t 1 and Cyb- $t 2$ are typical of a tele-mental approach Cyb-t3, Cyb- $t 4$ and Cyb-t5 are very recent and are representing a novelty. The reader alone can try to activate, for example, researches on the WEB and to realize as very recently, in about two years, the offers of solutions for Cyb- $\mathrm{t} 3$ and Cyb- $\mathrm{t} 4$ (alone or integrated with the traditional components Cyb-t1 and Cyb-t2) are exploded. Several are, when focusing to Cyb- $\mathrm{t} 3$, examples of companies widespreading new Apps products for tele-mental applications over the mobile-health based on a wearable into a pocket cyberspace, as for not exhaustive examples the ones (casually chosen) reported in (18-22). Also big companies are moving in this field, at the moment of the writing of this piece, for example, Google ${ }^{\circledR}$ is releasing a version of google map ${ }^{\circledR}$ with the AR embedded: think the usefulness for some mental disease such as the Alzheimer disease! As a not exhaustive example of Apps for Cyb-t4 we can consider QualityTime - My Digital Diet (23) available in the Google play store that allows a correct and aware smartphone use, monitoring the time, inserting alerts, extracting reports you can exchange with the therapist. On the other hand, regarding Cyb- $t 5$, it has become very easy to develop tests through eSs. For example using Form 

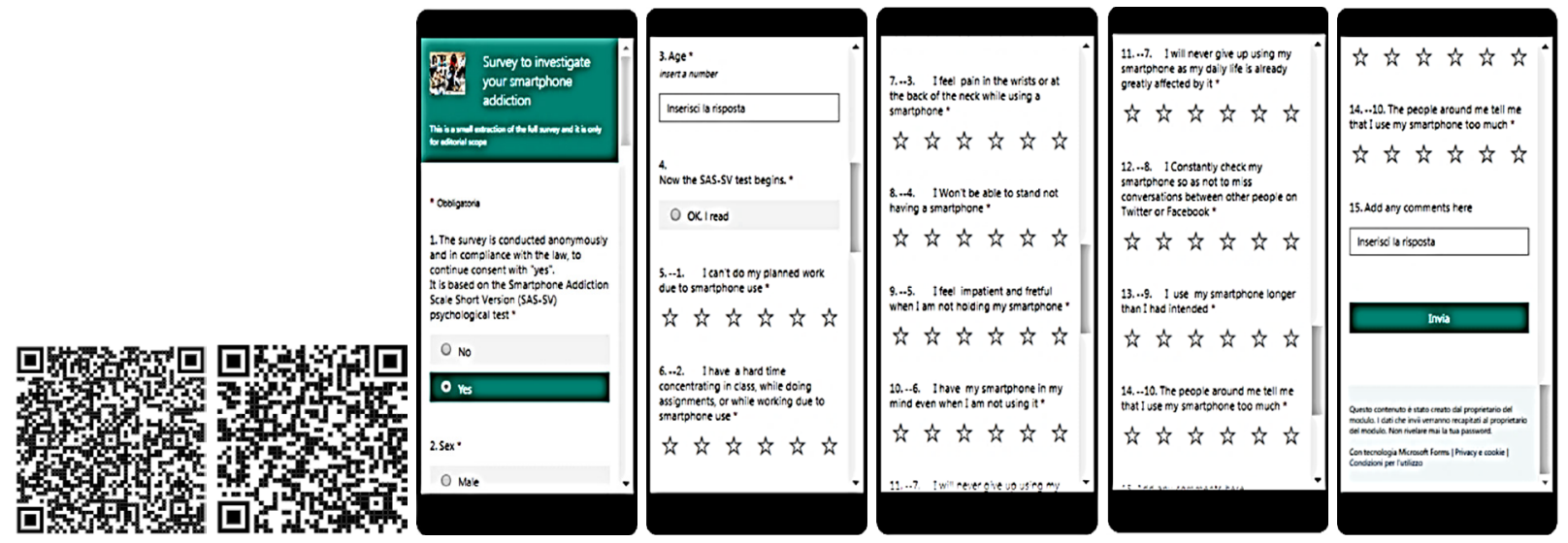

Figure 2 The eS: the QR codes of the eS and of the report; the print screens of the eS (PLEASE TRY the eS).

(Microsoft, USA) it is possible to make a simple eS and diffuse it through for example WhatsApp, obtaining an electronic report automatically. For example it is possible to convert into an electronic version a test used on adolescents and young adults to assess the smartphone addiction "the smartphone addiction scale short version” (SAS-SV) $(17,23)$. Figure 2 shows: the QR code that the reader can directly try and (b) the print screens of how the eS appears in the device. Link of the eS: https://forms.office.com/Pages/ ResponsePage.aspx?id=DQSIkWdsW0yxEjajBLZtrQAAA AAAAAAAAAZAAOUXdFhURVpWTVhFTDBRUEFO UFYzSIVXWEsyWjJaMC4u; link of the eS report: https:// forms.office.com/Pages/AnalysisPage.aspx?id=DQSIkWdsW 0yxEjajBLZtrQAAAAAAAAAAAAZAAOUXdFhURVpWT VhFTDBRUEFOUFYzSIVXWEsyWjJaMC4u\&AnalyzerT oken=iqzeoLQAAHfJC7uGHEYtfJXtXaSdhoPS.

\section{How to face these evolutions: the questions to the international scholars, stakeholders, regulation bodies and work groups}

The evolution in this field of mHealth, as it has been highlighted, is quit rapid and it is strongly hooked to the technology innovation: what it is futurist become reality in a couple of years! In particular we are here assisting to the integration of new components of care in mobile-health based on Cyb-Psy. It is particularly evident the mutation if we consider that the Cyberspace used in Cyb-t is migrating from the large environments of the cave directly into the smartphone becoming a Cyberspace wearable into a pocket. The citizen must be helped with clarification initiatives to avoid to lost her or him into the Apps that rapidly is going to grow (24) in number also in some field of tele-mental health (25).

The opinion and voice of professionals' actors is surely basic in this field. The role of the mHealth will be essential starting from the research up to the standardization/ regulation initiatives.

Certainly the scholars, the stake-holders, regulation bodies and workgroups from the scientific societies will be called to (I) answer to key-questions on the prevention of the new pathologies and disturbs from smartphone abuse $(15-17,23)$, using the same means of the mobiletechnologies to provide solutions based on mobilehealth; (II) to develop solutions for the design, modelling, assessment and regulation in this field.

An important point in the prevention will be surely to design initiatives, also based on (III) e-learning processes particularly dedicated to young people. Surely will be also necessary to apply properly scientific tools, provided by the research as, for example, the exercises of scientific positioning. Useful will be, therefore, to activate before all, (IV) wide range initiatives of positioning based on the exercises of scientific positioning that could involve all the actors, to fix a first preliminary map-point from which to starts.

It is very probable that many are moving in the directions (I-IV) and that therefore we will see scientific disseminations of guidelines and/or other policy documents very soon.

APA for example, at the moment of the writing of this contribution is announcing that will be forming an Expert Panel for its forthcoming resource, APA App Advisor, based on its App Evaluation Model (26), an important action in 
this direction that shows great attention to the phenomenon highlighted here.

At the moment at the Istituto Superiore di Sanità, the Italian National Institute of Health we have developed training initiatives, focused to young adolescents in the secondary schools also focused to the prevention on mental health [see PS01 on the web links $(27,28)]$ and currently we are developing a wide-range positioning exercise using dedicated eSs that we are currently submitting to actors (citizens and professionals) in this field.

\section{Acknowledgments}

Funding: None.

\section{Footnote}

Conflicts of Interest: DG serves as an unpaid editorial board member of mHealth from May 2019 to Apr. 2021.

Ethical Statement: The author is accountable for all aspects of the work in ensuring that questions related to the accuracy or integrity of any part of the work are appropriately investigated and resolved.

Open Access Statement: This is an Open Access article distributed in accordance with the Creative Commons Attribution-NonCommercial-NoDerivs 4.0 International License (CC BY-NC-ND 4.0), which permits the noncommercial replication and distribution of the article with the strict proviso that no changes or edits are made and the original work is properly cited (including links to both the formal publication through the relevant DOI and the license). See: https://creativecommons.org/licenses/by-ncnd/4.0\%.

\section{References}

1. Myers K, Nelson EL, Rabinowitz T, et al. American Telemedicine Association Practice Guidelines for Telemental Health with Children and Adolescents. Telemed J E Health 2017;23:779-804.

2. Shore JH, Yellowlees P, Caudill R, et al. Best Practices in Videoconferencing-Based Telemental Health April 2018. Telemed J E Health 2018;24:827-32.

3. Shore JH, Mishkind MC, Bernard J, et al. A lexicon of assessment and outcome measures for telemental health. Telemed J E Health 2014;20:282-92.
4. ATA Telehealth Resource Toolbox. 2017. Available online: www.americantelemed .org/main/policy-page/state-policyresource-center/additional-state-resources

5. Turvey C, Yellowlees P, Shore JH, et al. Delivering online video based mental health services. American Telemedicine Association Learning Center, 2014. Available online: http://learn.americantelemed.org/diweb/catalog/item/ $\mathrm{id} / 241193 / \mathrm{q} / \mathrm{o}=\mathrm{n} \% 26 \mathrm{c}=96 \% 26 \mathrm{t}=3359$

6. Turvey C, Coleman M, Dennison O, et al. ATA practice guidelines for video-based online mental health services. Telemed J E Health 2013;19:722-30.

7. Yellowlees P, Shore J, Roberts L. Practice guidelines for videoconferencing-based telemental health-October 2009. Telemed J E Health 2010;16:1074-89.

8. The American Telemedicine Association. Evidencebased practice for telemental health, 2009. Available online: https://higherlogicdownload.s3.amazonaws.com/ AMERICANTELEMED/618da447-dee1-4ee1-b941c5bf3db5669a/Uploadedlmages/New\%20Guideline\%20 Cover\%20May\%2017/NEWATA\%20Evidence\%20 Based\%20Practice.pdf

9. APA Telepsychiatry Toolkit. 2016. Available online: www. psychiatry.org/psychiatrists/practice/telepsychiatry

10. American Psychiatric Association, Resource document on telepsychiatry and related technologies in clinical psychiatry, 2014. Available online: https://www.psychiatry. org/File\%20Library/Psychiatrists/Directories/Libraryand-Archive/resource_documents/Resource-2014Telepsychiatry-Clinical-Psychiatry.pdf

11. American Psychiatric Association. Telemental health via videoconferencing. 1998.

12. Wiederhold BK. editor. Special issue on Virtual Reality. Cyberpsychology, Behavior, and Social Networking, VOLUME 22, ISSUE 1/JANUARY 2019.

13. Wiederhold MD. editor. Special issue on Augmented Reality, Cyberpsychology, Behavior, and Social Networking, VOLUME 22, ISSUE 2/FEBRUARY 2019.

14. Ventura S, Baños RM, Botella C. Chapter 7. Virtual and Augmented Reality: New Frontiers for Clinical Psychology in "State of the Art Virtual Reality and Augmented Reality Knowhow" BOOK editor Nawaz Mohamudally, INTECOPEN.

15. Peper E, Harvey R. Digital addiction: increased loneliness, anxiety, and depression. Neuroregolation 2018;5:3-8.

16. Elhai JD, Dvorak RD, Levine JC, et al. Problematic smartphone use: conceptual overview and systematic review of relations with anxiety and depression psychopathology. 
Journal of Affective Disorders 2017;207:251-9.

17. Giansanti D, Grigioni M. editors. Health in the palm of your hand: new risks from technology. Roma: Istituto Superiore di Sanità; 2018. (Rapporti ISTISAN 18/21) (in Italian).

18. Available online: https://www.limbix.com/ (last access "date of submission").

19. Available online: https://psious.com/ (last access "date of submission").

20. Available online: https://www.idego.it/virtual-reality/ (last access "date of submission").

21. Available online: https://virtuallybetter.com/mobile-vrsuite/ (last access "date of submission").

22. Available online: https://play.google.com/store/apps/ details?id=com.zerodesktop.appdetox.qualitytime\&hl=it

23. Kwon M, Kim DJ, Cho H, et al. The smartphone

doi: $10.21037 /$ mhealth.2019.11.02

Cite this article as: Giansanti D. Towards the evolution of the mHealth in mental health with youth: the cyber-space used in psychological rehabilitation is becoming wearable into a pocket. mHealth 2020;6:18. addiction scale: development and validation of a short version for adolescents. PloS One 2013;8:e83558.

24. Giansanti D. Introduction of medical Apps in telemedicine and e-health: problems and opportunities. Telemed J E Health 2017;23:773-6.

25. J Torous, P. Cerrato, J. Halamka Targeting depressive symptoms with technology, The Mhealth, 2019.

26. Available online: https://www.psychiatry.org/psychiatrists/ practice/mental-health-apps/app-evaluation-model (last access "date of submission").

27. Available online: http://old.iss.it/binary/publ/cont/ catalogo_DEFINITIVO_per_web.pdf (last access "date of submission").

28. Available online: https://scuolaericerca.iss.it/ps01-losmartphone-un-amico-ma-non-troppo/ (last access "date of submission"). 